\title{
Recreational and Cultural Use of the Forests
}

\section{by}

\author{
Kenneth A. Brynaert ${ }^{1}$
}

\begin{abstract}
Natural renewable resources are valuable national assets which form a part of Canadian culture and afford the opportunity for recreational and economic pursuits. The direction, however, in which our wildlife and forestry management practices and technology has taken us, over the past thirty-five to forty years, is fraught with serious pitfalls. If our country is to recover and restore the viability of our renewable natural resources, it is essential to seek a new approach whereby the utilization and management of these resources are founded upon the principles contained in the World Conservation Strategy. Inherent in that approach must be a clear understanding of all forest values, none of which may be discounted for single-interest benefits. The forestry industry must recognize that exercising its right to utilize timber resources embodies a responsibility not to degrade or infringe upon the legitimate interests of other resource users.
\end{abstract}

Key words: recreation, forest management, cultural values, wildlife management.

\section{Introduction}

Canadians have a deep philosophical attachment to wildlife, and a broad interest in its welfare and management. Most Canadians feel that wild life is important to them, as a symbol of a desirable quality of life and, more specifically, for the recreational opportunities, economic benefits, and pleasure that wildlife provides. Wildlife is a great Canadian heritage, a legacy received from our ancestors to be passed unimpaired to future generations. Most Canadians wish to ensure that wild life will always exist in something like its present diversity and distribution. This attitude reflects the principle of stewardship in our cultural heritage.

If this wish is to be realized, and our nation is to prosper. economically and spiritually, wildlife and wildlife habitat must receive wise and proper management. There is clear evidence that this imperative is being recognized by a growing body of Canadians in government and throughout the country. It was the primary concern that led the 44th and subsequent federal-provincial wildlife conferences towards articulation of the "Guidelines for Wildlife Policy in Canada." The desire of

Executive Vice-President, Canadian Wildlife Federation, 1673 Carling Ave. Ottawa, Ontario K2A 1C4. Delivered by Ed Mankelow.
Canadians to ensure the perpetuation of wildlife and wildlife habitat is also documented in many other forms.

The objects of the Canadian Wildlife Federation state in part:

to foster an understanding of natural processes so that people may live in harmony with the land, using and husbanding its renewable natural resources in a manner which maintains its productivity and its beauty for the long-term benefit and enrichment of society.

Similar statements of purpose and intent provide the direction for many other nongovernmental organizations in Canada. Governments, in reviewing their respective roles and responsibilities, are also confronted by the growing awareness among Canadians of the need for greater accountability and action in the stewardship and conservation of our wildife resources.

\section{Wildlife Values}

A dominant part of our society appears to be preoccupied with the need to place a dollar value on everything to assess its worth. Where expedient, values not clearly defined and accountable are considered expendable and often ignored. For the most part, wildlife agencies and other concerned groups have been slow to respond to this need to identify and define wildlife values in a way that makes them recognizable as assets that cannot be ignored.

Wildlife is a national asset, with economic, recreational, social, cultural and spiritual values for Canadians. But apart from its status as a resource, wildlife in its various and sundry forms has a value for its own sake, as a vital part of our biosphere. We share the environment with wildlife and we must be conscious of all its values, not just those that can be converted directly into dollars.

CWF has been compiling information on wildlife values, including fish, animals and plant products, excluding timber production. A 1980 unpublished paper "Estimated Annual Economic Benefit Derived From Wildlife" identified a value of $\$ 9.5$ billion. However, according to the 1981 national survey "The Importance of Wildlife to Canadians" initial CWF estimates were too conservative. Moreover, the absence of good data on the value of subsistence use, makes it extremely difficult to estimate accurately the full value of wildlife to Canadians.

It can be safely stated, however, that wildlife values are substantial, significantly more than $\$ 10$ billion annually, and are too important to Canadians to be ignored. Proper recognition of these wildlife values, combined with good management, should further enhance them. Surely Canadians do not have to put a price tag on wild life's cultural and spiritual values to ensure their recognition and protection. 


\section{Inadequacies of Management}

Canadians are becoming increasingly aware of the historical inadequacies of forest management and the narrow interests that have been pursued in exploiting timber resources. A series of articles in Harrowsmith magazine provide an insight into the process and results. The harvesting phase of the forest industry has gone from a labour intensive operation to one that is increasingly capital intensive and mechanized. In this transition, timber renewal and other forest-based values have been sacrificed for technological progress and a mad scramble to balance the books.

With due respect to wildlife professionals, where recognition is warranted, the management of wildlife and wildlife habitat has deteriorated in concert with forest management. Where success has been achieved, it has most often been obtained in spite of, rather than because of enlightened forest management. Professionals, both foresters and wild lifers, who seek to intercede in the interests of conserving broad forest values, may also be sacrificed, or be forced to accept poor management decisions.

Forest and wildlife managers cannot look back with any pride upon their achievements over the past 30 years in fostering the integration of forest and wildlife management. This inadequacy has not gone unnoticed. Canadians across the country are reacting to what they perceive to be a threat to their heritage. Some respond by seeking to preserve what little remains of our better forest resources, as manifest in the move to establish more and more parks. Others react by endeavouring to change the system, to introduce integrated management, and to restore the resource base damaged by mismanagement.

The preservationist concept of conservation embodies a negative, defeatist attitude which implies that nothing can be done to recover and restore damaged resources. CWF cannot accept that philosophy. Renewable natural resources have a dynamic potential that can and does respond to management. No form of life exists in isolation. All require nutrients, water, air, shelter and space, and have specific tolerances to factors such as temperature, humidity, sunlight and the presence of toxic substances. The distribution, abundance and welfare of each species of plant and animal are determined by the extent to which these requirements are met, and by the abundance and distribution of other species with which each is ecologically linked.

Just as no form of life exists in isolation, no form of management can be successfully applied in isolation from all the factors that operate within the environment. Attainment of single-interest objectives, such as timber production, must necessarily affect other forms of life. Certain natural processes operate to produce a mix of renewable natural resources. We need to recognize those natural processes and to be aware of the consequences attending efforts to short-circuit those processes. Thus the integration of forest and wildlife management is essential to the future prosperity of both. The continued enjoyment of economic, recreational and cultural benefits from our forest resources depends upon how well we react to this prime essential.

\section{A New Approach}

Obviously the direction that management and technology has taken us, over the past $35-40$ years, is fraught with serious pitfalls. If we are to recover our sense of values and restore the viability of our forest resources, we must seek a new approach and direction. Inherent in that approach must be a clear recognition of all forest values, none of which can be discounted in the quest for single-interest benefits. We must adopt an ecological approach to renewable resource use and management. Any other road leads to certain destruction.

Renewable natural resources are not the property of any one government, political party, industry or segment of society. They are a valuable national asset which forms part of our Canadian heritage. Canadians must adopt a philosophy that embodies the inseparability of conservation and development. Governments must come to recognize that their authority to allocate resources embodies the responsibility to ensure that allocation does not jeopardize the welfare of other resources. The forest industry must recognize that exercising its right to utilize timber resources also embodies the responsibility to ensure it does not degrade other resources or infringe upon the interests of other resource users.

Our approach to the utilization and management of renewable natural resources must be founded on the principles embodied in the World Conservation Strategy (1980), and ensure these principles are reflected in our own national and subnational strategies. The place to start this process is right at home, where we live and where we work. Renewable resource users must first put their own house in order, examine their own goals and broaden their scope and commitment. Canadians can then, jointly, confront the problems that now threaten our best interests. Apart from ineffective management and shortsighted land use, these problems include water and air pollution, indiscriminate use of biocides and synthetic chemicals, industrial and toxic waste disposal, and our callous disregard for conservation ethics.

It is the view of CWF that we have already done enough talking, it is now time for action. We must discard our antiquated views about special interests and think about what is best for the nation and the future of our country. We know what the problems are; jointly and severally, we must get on with the job of creating solutions. Conservation ethics must become an essential element of our philosophy.

\section{Reference \\ IUCN 1980. World Conservation Strategy. International Union for the Conservation of Nature, 1196 Gland, Switzerland.}

